\title{
The use of the practice walk test in pulmonary rehabilitation program: National COPD Audit Pulmonary Rehabilitation Workstream
}

This article was published in the following Dove Press journal:

International Journal of COPD

8 September 2017

Number of times this article has been viewed

\author{
Ali Hakamy ${ }^{1,2}$ \\ Tricia M McKeever ${ }^{2}$ \\ Michael C Steiner ${ }^{3}$ \\ C Michael Roberts ${ }^{4}$ \\ Sally J Singh ${ }^{3}$ \\ Charlotte E Bolton'
}

'Nottingham Respiratory Research Unit, NIHR Nottingham Biomedical Research Centre, ${ }^{2}$ Division of Epidemiology and Public Health, School of Medicine, University of Nottingham, Nottingham, ${ }^{3}$ Leicester Respiratory Biomedical Research Unit, Institute for Lung Health, University Hospitals of Leicester NHS Trust, Leicester, ${ }^{4}$ Barts and the London School of Medicine and Dentistry, Queen Mary University of London, London, UK
Correspondence: Charlotte E Bolton Nottingham Respiratory Research Unit, NIHR Nottingham Biomedical Research Centre, University of Nottingham, Clinical Sciences Building, City Hospital NUH Trust Campus, Hucknall Road, Nottingham NG5 IPB, UK

Tel +44 II5823 I7I0

Email charlotte.bolton@nottingham.ac.uk
Abstract: Our aim was to evaluate the use and impact of the practice walk test on enrolment, completion, and clinical functional response to pulmonary rehabilitation (PR) using the 2015 UK National Chronic Obstructive Pulmonary Disease (COPD) Pulmonary Rehabilitation audit data. Patients were assessed according to whether a baseline practice walk test was performed or not. Study outcomes included use of the practice walk test, baseline and change in incremental shuttle walk test distance (ISWD) or 6-minute walk test distance (6MWD), and enrolment to and completion of PR program. Of 7,355 patients, only 1,666 (22.6\%) had a baseline practice test. At baseline, the practice walk test group walked further as compared to the no practice walk test group: ISWD, $17.9 \mathrm{~m}$ [95\% confidence interval (CI) 8.2-27.5 m] and 6MWD, $34.8 \mathrm{~m}$ (95\% CI 24.7-44.9 m). The practice walk test group were 2.2 times (95\% CI 1.8-2.6) more likely to enroll and $17 \%(95 \%$ CI 1.03-1.34) more likely to complete PR. Although the change in ISWD and 6MWD with PR was lower in the practice walk test group, they walked further at discharge assessment. Only $22.6 \%$ of the patients in the 2015 National PR audit had a practice walk test at assessment. Those who did had better enrolment, completion, and better baseline walking distance, from which the prescription is set.

Keywords: pulmonary rehabilitation, COPD, functional performance test, functional exercise test

\section{Introduction}

Pulmonary rehabilitation (PR) has become firmly established as a core management strategy for patients with COPD. ${ }^{1}$ In clinical practice, the PR program should include outcome assessments to determine patient progress during the program including measures of functional performance, breathlessness, and health-related quality of life. ${ }^{1}$

Field exercise tests, such as the 6-minute walk test (6MWT) and incremental shuttle walk test (ISWT), are commonly used to assess changes in the functional performance among patients with COPD undergoing PR. ${ }^{2-4}$ Both tests have demonstrated their validity and reliability and are sensitive to improvement following PR. ${ }^{5}$ Importantly, these tests are also the platform for individually prescribing the tailored exercise program, ${ }^{6,7}$ in order to deliver the intensity of training required to gain physiological benefit. A recent systematic review determined a learning effect when two or more functional exercise tests are conducted ${ }^{5}$ - a mean improvement of $20 \mathrm{~m}$ on the second ISWT and $26 \mathrm{~m}$ on the second 6MWT. This learning effect is large enough to be clinically important when they are used to prescribe exercise and evaluate 
the improvement due to PR intervention. ${ }^{5}$ As a result, at least one practice functional exercise test at assessment is recommended. ${ }^{7}$

Currently, there is insufficient evidence evaluating the effect of the practice walk test at assessment on enrolment and completion of PR. The study hypothesized that the group having a practice walk test at assessment would have a better baseline exercise test with which to base the exercise prescription and, thereby, evaluate impact on the clinical response to $\mathrm{PR}$.

This study aimed to address, in real-life practice, the use and impact of a practice walk test on 1) the baseline exercise test; 2) enrolment and completion; and 3) clinical response to $\mathrm{PR}$, particularly with regard to the functional assessment.

\section{Methods}

\section{Data source}

Data from the 2015 National COPD Audit Program's PR workstream, carried out across England and Wales, were used for this study. ${ }^{8,9}$ It includes both the organizational audit data and the clinical audit of patients who were referred to PR between 12 January and 10 April 2015 from the 210 PR programs that participated. Approval from the Caldicott Guardian was obtained from each participating unit before access to the online audit web tool was granted and, following National Confidentiality Advisory Group advice, patients enrolled to the audit and provided individual written informed consent before their data were uploaded.

\section{Demographics and clinical characteristics}

The identified patient demographic and clinical variables included the following: age (four categories: $<60,60$ to $<70$, 70 to $<80$, and $\geq 80$ years), gender, Medical Research Council (MRC) dyspnea score, smoking status (current, ex, never, or not recorded), forced expiratory volume in 1 second $\left(\mathrm{FEV}_{1}\right)$ percent predicted, selected comorbidities [atrial fibrillation (AF), diabetes (DM), ischemic heart disease (IHD), and left ventricular failure (LVF)], whether long-term oxygen therapy was used, the functional exercise tests (6MWT and ISWT), enrolment to PR and completion of PR (as reported by the PR team), proportion of sessions attended out of sessions scheduled and then categorized as $(\leq 50 \%, 51 \%-75 \%$, and $>75 \%$ ), and health status measures (St George's Respiratory Questionnaire, and the COPD Assessment Test).

The type of PR (whether cohort, rolling, or other) was recorded in two ways: in the analyses at assessment, the type of PR for that program was used from organizational data, as some individuals who did not enroll would not have this data; therefore, for everyone, it was decided that organizational data would be used. For those who enrolled, the type of PR was recorded as the actual PR program the patient underwent (from clinical data). Patients were divided into two groups depending on whether they have had a practice walk test at the assessment ("Practice test" versus "No practice test"). (Further information on the audit can be found in Appendix 1).

Data were described in terms of proportion and mean (standard deviation [SD]) as appropriate. Logistic regression was used to examine the practice test effect on enrolment, starting, and completion of PR between those who had the practice test at assessment versus those with no practice tests. Potential confounders that changed the relation between practice test and enrolment, starting, and completion of PR by more than $10 \%$ were entered into a final multivariate model to calculate the adjusted odds ratios (aOR). Linear regression was used to further explore the relationship between the practice test and ISWD and 6MWD with $\beta$ regression coefficients and their $95 \%$ confidence intervals (CI). All statistical analysis was performed using the Stata version 13 software (StataCorp LP, College Station, TX, USA).

\section{Results}

\section{Demographic and clinical differences}

The audit collected data from 7,413 patients; 58 of these patients had no record of whether they had a practice test at assessment and were thus excluded; 7,355 patients were included; 1,666 (22.6\%) had a recorded "Practice test" compared to $5,689(77.3 \%)$ with "No practice test." Demographic and clinical characteristics between the two groups are listed in Table 1. The significant differences were that the group who performed a practice test at assessment were more likely to be male and have severe airflow obstruction. Those who performed a practice test at assessment were more likely to be referred to the PR program which, in the organizational data, stated they offered both the cohort and rolling type of PR program.

\section{ISWT and 6MWT at baseline}

Among 3,812 patients who had ISWT and 2,835 patients with 6MWT at assessment, both the ISWD and 6MWD at baseline were significantly greater in the practice test group compared to the no practice test group. After adjusting for age, gender, and type of PR program, linear regression demonstrated that the difference between the two groups was maintained (ISWD; $\beta$ coefficient $17.9 \mathrm{~m} ; 95 \%$ CI 8.2-27.5; $P<0.0001$ ) (6MWD; $\beta$ coefficient 34.8 m; 95\% CI 24.7-44.9; $P<0.0001)$. 
Table I Demographic and clinical characteristics of patients according to whether they had a practice test at baseline assessment $(n=7,355)$

\begin{tabular}{|c|c|c|c|}
\hline & $\begin{array}{l}\text { Practice test } \\
\mathrm{n}=1,666 \mathrm{n}(\%)\end{array}$ & $\begin{array}{l}\text { No practice test } \\
n=5,689 n(\%)\end{array}$ & $P$-value \\
\hline \multicolumn{4}{|l|}{ Age category (years) } \\
\hline$<60$ & $266(I 5.9)$ & $969(17.0)$ & 0.307 \\
\hline $60-<70$ & $593(35.5)$ & $2,087(36.6)$ & \\
\hline $70-<80$ & 599 (35.9) & $2,000(35.1)$ & \\
\hline$\geq 80$ & $208(12.4)$ & $632(11.1)$ & \\
\hline Missing & 0 & 1 & \\
\hline \multicolumn{4}{|l|}{ Gender } \\
\hline Male (\%) & 961 (57.6) & $2,952(51.8)$ & $<0.0001$ \\
\hline Female (\%) & $705(42.3)$ & $2,737(48.1)$ & \\
\hline $\mathrm{FEV}_{1} \%$ predicted & $\mathrm{N}=1,15 \mathrm{I}$ & $\mathrm{N}=3,395$ & 0.003 \\
\hline Mean (SD) & $53.1(19.1)$ & $55.1(19.9)$ & \\
\hline GOLD I & $102(8.8)$ & $383(11.2)$ & 0.002 \\
\hline GOLD 2 & $504(43.7)$ & I,568 (46.I) & \\
\hline GOLD 3 & $421(36.5)$ & $1,122(33.0)$ & \\
\hline GOLD 4 & $124(10.7)$ & $322(9.4)$ & \\
\hline Not recorded & 515 & 2,294 & \\
\hline \multicolumn{4}{|l|}{ Smoking status } \\
\hline Never & $95(5.8)$ & $348(6.2)$ & 0.184 \\
\hline Ex-smoker & $\mathrm{I}, 20 \mathrm{I}(73.3)$ & 3,946 (7I.0) & \\
\hline Current smokers & $34 \mid(20.8)$ & $\mathrm{I}, 26 \mathrm{I}(22.7)$ & \\
\hline Not recorded & 29 & 134 & \\
\hline \multicolumn{4}{|l|}{ MRC baseline } \\
\hline MRC I \& 2 & $302(18.8)$ & $886(17.1)$ & 0.243 \\
\hline MRC 3 & $609(38.0)$ & $2,029(39.1)$ & \\
\hline MRC 4 & $533(33.3)$ & $\mathrm{I}, 780(34.3)$ & \\
\hline MRC 5 & $155(6.6)$ & $485(9.3)$ & \\
\hline Not recorded & 67 & 509 & \\
\hline \multicolumn{4}{|l|}{ Comorbidities } \\
\hline $\mathrm{AF}$ & $120(7.2)$ & $358(6.2)$ & 0.185 \\
\hline DM & $232(13.9)$ & $749(13.1)$ & 0.422 \\
\hline IHD & $180(10.8)$ & 648 (11.3) & 0.505 \\
\hline LVF & $42(2.5)$ & $147(2.5)$ & 0.886 \\
\hline \multicolumn{4}{|l|}{$\mathrm{O}_{2}$ use } \\
\hline Long-term oxygen & $66(3.9)$ & $227(3.9)$ & 0.958 \\
\hline \multicolumn{4}{|c|}{ Type of PR offered at that program (organizational audit) } \\
\hline Rolling only & $508(30.4)$ & $2,548(44.7)$ & $<0.000$ I \\
\hline Cohort only & $582(34.9)$ & $1,929(33.9)$ & \\
\hline Both types & $519(31.1)$ & I,I7I (20.5) & \\
\hline Only other & $57(3.4)$ & $4 \mathrm{I}(0.7)$ & \\
\hline \multicolumn{4}{|c|}{ Exercise test at baseline assessment } \\
\hline ISWD & $\mathrm{N}=1,004$ & $\mathrm{~N}=2,808$ & \\
\hline Mean (SD) & $214.1(134.4)$ & $193.1(133.3)$ & $<0.0001$ \\
\hline 6MWD & $\mathrm{N}=668$ & $N=2,167$ & \\
\hline Mean (SD) & $272.4(114.7)$ & $240.1(114.1)$ & $<0.000$ I \\
\hline Enrolment n (\%) & $1,519(91.1)$ & $4,762(83.7)$ & $<0.0001$ \\
\hline Commenced PR n (\%) & I,5I8 (9I.I) & $4,75 \mathrm{I}(83.5)$ & $<0.0001$ \\
\hline
\end{tabular}

Abbreviations: $\mathrm{FEV}$, forced expiratory volume in I second; SD, standard deviation GOLD, global initiative for obstructive lung disease; MRC, Medical Research Council Dyspnoea Score; AF, atrial fibrillation; DM, diabetes mellitus; IHD, ischemic heart disease; LVF, left ventricular failure; $\mathrm{O}_{2}$, oxygen; PR, pulmonary rehabilitation; ISWD, incremental shuttle walked distance; 6MWD, 6-minute walk distance.

\section{Enrolment and commencement of PR program}

Of the 7,355 patients, 6,269 (85.2\%) patients were enrolled and subsequently commenced the PR program; 1,518 (91.1\%) had a practice test and 4,751 (83.5\%) did not (Table 2). Of those patients who started PR, patients with a practice test were more likely to be male and have more severe airflow obstruction. In addition, patients were more likely to actually enroll onto a cohort type of PR program (clinical audit data). After adjusting for age, gender, and type of PR, logistic regression revealed that those patients with a practice test were twice as likely to enroll for PR than those with no practice test (aOR 2.2; 95\% CI 1.8-2.6). Sensitivity analyses in those who did an ISWT and then those who did a 6MWT separately were conducted, and included the baseline distance to see if this modified the relationship, which it did not.

\section{Completion of PR program}

Of the 6,269 patients who were enrolled, 4,426 (70.6\%) patients completed the PR program; there were 1,117 (73.5\%) patients who had a practice test compared to $4,751(69.6 \%)$ patients who did not (Table 2). After adjusting for age, gender, and type of PR program, the practice test group were $17 \%$ more likely to complete the PR program (aOR 1.17; 95\% CI 1.03-1.34). Furthermore, practice test patients attended more scheduled PR sessions $(P=0.021)$.

\section{Change in ISWD and 6MWD with PR}

In total, 2,251 patients had both a baseline and discharge assessment for ISWT, and 1,662 patients had both assessments for 6MWT. Overall, the mean improvement in ISWD was $63 \mathrm{~m}(95 \%$ CI 60.3-66.8 m) and for 6MWD it was $59 \mathrm{~m}$ (95\% CI 54.6-63.7 m). The MCID was achieved in 57\% of patients for ISWD and in 70\% for 6MWD. ${ }^{5,7,10}$

The change in the distance recorded was lower for both tests in the group who had undergone the practice test (Table 3). After adjusting for age, gender, and baseline

Table 2 Completion and number of sessions attended of pulmonary rehabilitation among patients who started pulmonary rehabilitation $(n=6,269)$

\begin{tabular}{|c|c|c|c|}
\hline & $\begin{array}{l}\text { Practice test } \\
N=I, 5 \mid 8 \mathrm{n}(\%)\end{array}$ & $\begin{array}{l}\text { No practice test } \\
n=4,75 \text { I } n(\%)\end{array}$ & $P$-value \\
\hline Completed PR n (\%) & I, II7 (73.5) & $3,309(69.6)$ & 0.003 \\
\hline \multicolumn{4}{|c|}{ Type of PR that patient underwent (clinical audit) } \\
\hline Rolling & $74 \mid(48.8)$ & $2,603(54.7)$ & 0.0002 \\
\hline Cohort & $731(48.1)$ & $2,00 \mathrm{I}(42.1)$ & \\
\hline Other & $46(3.0)$ & $147(3.0)$ & \\
\hline \multicolumn{4}{|c|}{ Proportion of session attended out of those scheduled } \\
\hline$\leq 50 \%$ & $290(19.1)$ & I,III (23.3) & 0.021 \\
\hline $51 \%-75 \%$ & $236(15.5)$ & $643(13.5)$ & \\
\hline$>75 \%$ & $992(65.3)$ & $2,997(63.1)$ & \\
\hline
\end{tabular}

Abbreviations: PR, pulmonary rehabilitation; ISWD, incremental shuttle walked distance; 6MWD, 6-minute walk distance. 
Table 3 Change in functional exercise tests stratified by practice test at assessment for patients who had both a baseline and discharge assessment test recorded

\begin{tabular}{|c|c|c|c|c|}
\hline \multirow[t]{2}{*}{ Mean (SD) } & \multicolumn{2}{|l|}{ ISWD } & \multicolumn{2}{|l|}{ 6MWD } \\
\hline & $\begin{array}{l}\text { Practice test } \\
n=626\end{array}$ & $\begin{array}{l}\text { No practice test } \\
n=1,625\end{array}$ & $\begin{array}{l}\text { Practice test } \\
n=4 \mid 4\end{array}$ & $\begin{array}{l}\text { No practice test } \\
n=I, 248\end{array}$ \\
\hline At baseline & $221 \mathrm{~m}(136)$ & 202 m (129) & $287 \mathrm{~m}(\mathrm{I} I 0)$ & $258 \mathrm{~m}(\mathrm{I} \mid 2)$ \\
\hline At discharge & $275 \mathrm{~m}(156)$ & $269 \mathrm{~m}(|5|)$ & 337 m (III) & $320 \mathrm{~m}(140)$ \\
\hline Change & 54 m (79) & $67 \mathrm{~m}(78)$ & $49 \mathrm{~m}(57)$ & $62 \mathrm{~m}(103)$ \\
\hline \multicolumn{5}{|c|}{ Difference of the change in functional exercise tests between the two groups } \\
\hline Unadjusted $\beta$ coefficient $(95 \% \mathrm{Cl})$ & \multicolumn{2}{|c|}{$-12.9 \mathrm{~m}(-5.6$ to -20.2$)$} & \multicolumn{2}{|c|}{$-12.5 \mathrm{~m}(-4.5$ to -20.5$)$} \\
\hline Adjusted $\beta$ coefficient $(95 \% \mathrm{Cl}) *$ & \multicolumn{2}{|c|}{$-12.3 \mathrm{~m}(-19.5$ to -5.1$)$} & \multicolumn{2}{|c|}{$-8.9 \mathrm{~m}(-19$ to 1.4$)$} \\
\hline
\end{tabular}

Note: *After adjusting for age, gender, and baseline exercise distance.

Abbreviations: m, meters; ISWD, incremental shuttle walked distance; 6MWD, 6-minute walk distance.

exercise tests, the practice test patients improved by $12.3 \mathrm{~m}$ less (ISWD) and $8.9 \mathrm{~m}$ less (6MWD) than the no practice patients (ISWD change, $\beta$ coefficient $-12.3 \mathrm{~m}, 95 \% \mathrm{CI}-19.5$ to $-5.1, P=0.001$; $6 \mathrm{MWD}$ change, $\beta$ coefficient $-8.9 \mathrm{~m}$, $95 \% \mathrm{CI}-19$ to $1.4, P=0.09)$. Patients who had the practice test were $41 \%$ more likely to improve on their MRC score (after adjusting for age and gender, aOR 1.41; 95\% CI 1.21-1.65), whereas there was no difference with regard to change in health status.

\section{Discussion}

Only $22.6 \%$ of the 7,355 patients in the 2015 National COPD PR audit had a practice walk test at baseline, despite recommendations that a practice test is required in such circumstances. ${ }^{7}$ Not only was the distance of the baseline exercise test greater in the group who underwent a practice walk test, but also were both enrolment and completion rates in this group. Although the change in recorded exercise performance was not greater in the patients with a practice test, they performed better at discharge assessment and were more likely to have an improvement in their dyspnea score.

The 2015 National COPD PR audit offers an opportunity to assess the role of the practice test in a large cohort of subjects within the UK who are undergoing PR. ${ }^{8}$ There is a strong recommendation for conducting at least one practice test prior to the formal assessment; yet, this was not systematically done in the 2015 audit. ${ }^{5,7}$ In 2000, a survey of 75 PR centers across Canada and the USA had reported a similar finding - that $80 \%$ of PR centers performed only one walk test. ${ }^{11}$ A more recent survey in Australia, reported in 2011, suggested a marginally better result - that $39 \%$ of $161 \mathrm{PR}$ programs performed two tests. ${ }^{12}$ However, the finding of both surveys and our study was underwhelming. There are a number of reasons for a center to choose to do or not do a practice test, and these are likely to be center-based decisions and may reflect educational, resource, or time constraints.
Studies have previously demonstrated that factors such as learning effect and motivation influence the exercise walking distance..$^{5,13,14}$ Improvements after a repeated test have not only been seen among patients with chronic respiratory disease, ${ }^{5}$ but also in healthy adults, ${ }^{15}$ and in patients with other medical conditions. ${ }^{16}$ The marked difference in the current study in baseline functional tests between the two groups is likely a result of the learning effect after the practice test. Unfortunately, the practice test distance was not recorded alongside the formal distance in order to ascertain the learning effect specifically.

Pulmonary rehabilitation programs prescribe exercise training based on the initial exercise assessment outcome. The lack of a practice test prior to the formal assessment of an exercise test will likely under-represent the distance, which then may lead to underestimating the training intensity and, thus, the patient's true training potential. ${ }^{7,17}$ This study shows an association between the functional exercise tests' distances at baseline and discharge and the practice test. One possible explanation for the greater change in the exercise tests in patients who did not perform a practice test was the incorporation of a learning effect into the overall change from baseline to post visit. It is possible to speculate, therefore, that, if this was removed from the overall PR gain, there was less impact of PR in the group without a practice test given that the difference at baseline was greater than the mean change. Furthermore, more patients improved their breathlessness score in the group who performed the practice test, suggesting better clinical improvement. Although improvements in dyspnea with PR are well recognized regardless of the patients' initial degree of dyspnea, ${ }^{1,18}$ this interesting finding associated with the practice test perhaps relates to the improved exercise prescription received.

Moreover, these data highlight the apparent impact of the practice walk test on enrolment and completion of PR. Factors that affect enrolment and completion of PR programs 
are widely recognized and include transportation to the PR center, social deprivation, smoking status, and level of comorbidities. ${ }^{19-23}$ The findings here demonstrate that the practice walk test was also associated with enrolment and completion of PR.

\section{Strengths and limitations}

The strength of this study was that the audit is comprehensive, large, and representative of the UK, with over 7,000 individuals attending an assessment for PR. However, differences exist among PR programs across countries. There might be other quality or process factors influencing both the conduct of the practice walk test and the outcomes including staffing or other resources that are not directly possible to analyze here. In addition, the actual distance value of the practice walk test was not recorded, and we know very little about practicalities such as the timing of the procedure or the reasons why a practice was not performed.

\section{Conclusion}

Only $22.6 \%$ of patients being assessed for PR had a practice test prior to their exercise assessment. The practice test impacts on clinical outcomes and, thus, is not a trivial issue. Although this may be a measure of broader service quality, its utility in reliably setting an exercise prescription cannot be ignored. There are important clinical implications of this work for the conduct of PR. This work robustly demonstrates the role of the practice walk test in the baseline assessment of PR to maximize the benefits of the program. Following awareness of the impact of the practice walk test, there will be educational, practical, and resource issues that need consideration to implement this across the programs. Finally, given that PR is central to the management of COPD, the technical standards for the performance of exercise tests need to be understood and implemented by rehabilitation practitioners in the field.

\section{Acknowledgments}

The National COPD Audit Program is commissioned by the Healthcare Quality Improvement Partnership (http://www. HQIP.org.uk) as part of the National Clinical Audit Program. The authors gratefully acknowledge the Royal College of Physicians COPD team who managed the audit collection and database. In particular, the authors would like to thank Juliana Holzhauer-Barrie, Viktoria McMillan, Muhammad Saleem Khan, and Emma Skipper. The authors would also like to acknowledge the pulmonary rehabilitation work-stream group. This study is based on data collected by or on behalf of the Healthcare Quality Improvement Partnership, who have no responsibility or liability for the accuracy, currency, reliability, and/or correctness of this study. This study is supported by both the National Institute for Health Research (NIHR) Nottingham and Leicester Biomedical Research Centers. The views expressed are those of the authors and not necessarily of the National Health Service, the NIHR, or the Department of Health. No other support was received from any other organization for the submitted work.

\section{Author contributions}

CEB and TMM devised the original idea and contributed to the design of the study and analysis of the data. AH, CEB, and TMM developed the analysis plan. AH did the data processing. CMR is the lead for the National COPD audit and assisted with the submission to HQIP for data. MCS is the lead for the pulmonary rehabilitation workstream of the National COPD audit, and SJS and CEB are members of the pulmonary rehabilitation audit workstream. AH, CEB, and TMM drafted the first draft. All authors contributed toward data analysis, drafting and revising the paper and agree to be accountable for all aspects of the work.

\section{Disclosure}

$\mathrm{AH}$ has carried out this study as part of his $\mathrm{PhD}$ program at University of Nottingham. He has received a scholarship award from Ministry of Education (Saudi Arabia). The authors report no other conflicts of interest in this work.

\section{References}

1. Bolton CE, Bevan-Smith EF, Blakey JD, et al; British Thoracic Society Pulmonary Rehabilitation Guideline Development Group; British Thoracic Society Standards of Care Committee. British Thoracic Society guideline on pulmonary rehabilitation in adults. Thorax. 2013; 68(Suppl 2):ii1-ii30.

2. Lacasse Y, Goldstein R, Lasserson TJ, Martin S. Pulmonary rehabilitation for chronic obstructive pulmonary disease. Cochrane Database Syst Rev. 2006;4(4):CD003793.

3. Singh S. The use of field walking tests for assessment of functional capacity in patients with chronic airways obstruction. Physiotherapy. 1992;78(2):102-104

4. Singh SJ, Smith DL, Hyland ME, Morgan MD. A short outpatient pulmonary rehabilitation programme: immediate and longer-term effects on exercise performance and quality of life. Respir Med. 1998; 92(9):1146-1154

5. Singh SJ, Puhan MA, Andrianopoulos V, et al. An official systematic review of the European Respiratory Society/American Thoracic Society: measurement properties of field walking tests in chronic respiratory disease. Eur Respir J. 2014;44(6):1447-1478.

6. Gloeckl R, Marinov B, Pitta F. Practical recommendations for exercise training in patients with COPD. 2013;22(128):178-186.

7. Holland AE, Spruit MA, Troosters T, et al. An official European Respiratory Society/American Thoracic Society technical standard: field walking tests in chronic respiratory disease. Eur Respir J. 2014; 44(6):1428-1446. 
8. Royal College of Physicians. National COPD Audit Programme: Pulmonary rehabilitation workstream Steps to breathe better Clinical Audit 2016. Available from: http://bit.ly/1NMbNqU. Accessed August 09, 2017.

9. National COPD Audit Programme: Resources and organisation of Pulmonary Rehabilitation services in England and Wales 2015. Available from: http://bit.ly/1MhG1EJ. Accessed August 09, 2017.

10. Singh SJ, Jones PW, Evans R, Morgan MD. Minimum clinically important improvement for the incremental shuttle walking test. Thorax. 2008;63(9):775-777.

11. Elpern EH, Stevens D, Kesten S. Variability in performance of timed walk tests in pulmonary rehabilitation programs. Chest. 2000;118(1): 98-105.

12. Johnston CL, Maxwell LJ, Alison JA. Pulmonary rehabilitation in Australia: a national survey. Physiotherapy. 2011;97(4):284-290.

13. Steele B. Timed walking tests of exercise capacity in chronic cardiopulmonary illness. J Cardiopulm Rehabil. 1996;16(1):25-33.

14. Sciurba F, Criner GJ, Lee SM, et al; National Emphysema Treatment Trial Research Group. Six-minute walk distance in chronic obstructive pulmonary disease: reproducibility and effect of walking course layout and length. Am J Respir Crit Care Med. 2003;167(11):1522-1527.

15. Wu G, Sanderson B, Bittner V. The 6-minute walk test: how important is the learning effect? Am Heart J. 2003;146(1):129-133.

16. Katzel LI, Sorkin JD, Macko RF, Smith B, Ivey FM, Shulman LM. Repeatability of aerobic capacity measurements in Parkinson disease. Med Sci Sports Exerc. 2011;43(12):2381-2387.
17. Dyer F, Marriner P, Cheema K, Bott J. Is a practice incremental shuttle walk test really necessary? Chron Respir Dis. 2011;8(3): 201-205.

18. Evans RA, Singh SH, Collier R, Williams JE, Morgan MD. Pulmonary rehabilitation is successful for COPD irrespective of MRC dyspnoea grade. Respir Med. 2009;103(7):1070-1075.

19. Selzler AM, Simmonds L, Rodgers WM, Wong EY, Stickland MK. Pulmonary rehabilitation in chronic obstructive pulmonary disease: predictors of program completion and success. COPD. 2012;9(5): 538-545.

20. Keating A, Lee AL, Holland AE. Lack of perceived benefit and inadequate transport influence uptake and completion of pulmonary rehabilitation in people with chronic obstructive pulmonary disease: a qualitative study. J Physiother. 2011;57(3):183-190.

21. Steiner MC, Lowe D, Beckford K, et al. Socioeconomic deprivation and the outcome of pulmonary rehabilitation in England and Wales. Thorax. 2017;72(6):530-537.

22. Brown AT, Hitchcock J, Schumann C, Wells JM, Dransfield MT, Bhatt SP. Determinants of successful completion of pulmonary rehabilitation in COPD. Int J Chron Obstruct Pulmon Dis. 2016;11: 391-397.

23. Sohanpal R, Seale C, Taylor SJ. Learning to manage COPD: a qualitative study of reasons for attending and not attending a COPDspecific self-management programme. Chron Respir Dis. 2012;9(3): $163-174$.
International Journal of COPD

\section{Publish your work in this journal}

The International Journal of COPD is an international, peer-reviewed journal of therapeutics and pharmacology focusing on concise rapid reporting of clinical studies and reviews in COPD. Special focus is given to the pathophysiological processes underlying the disease, intervention programs, patient focused education, and self management protocols.

\section{Dovepress}

This journal is indexed on PubMed Central, MedLine and CAS. The manuscript management system is completely online and includes a very quick and fair peer-review system, which is all easy to use. Visit http://www.dovepress.com/testimonials.php to read real quotes from published authors. 